\title{
Penerapan Trainer Human Machine Interface (HMI) Berbasis CX-Designer Sebagai Media Pembelajaran Programmable Logic Controller (PLC)
}

\author{
Angga Septian MN \\ Teknik Informatika, Universitas Pamulang, Jl. Raya Puspitek No. 46, Buaran, Serpong, Indonesia \\ e-mail: anggaseptianmn@gmail.com
}

\begin{abstract}
The purpose of this research is to create a learning media design in the Programmable Logic Controller (PLC) lecture in the form of CX-Designer-based Human Machine Interface (HMI) trainer integrated with CX-Programmer. The appropriate HMI design will make the program trial work easier and more efficient. The effectiveness of HMI as a learning media provides the information needed, so that the planning can run with maximum efficiency. The research method used is an experimental method with a design to make a product in the form of a trainer to test a program that has been designed by the operator. The results of this study can be concluded that the use of CX-Designer-based HMI trainers can be used in understanding the logic circuit of a program very easily and quickly in practicing programming skills in the PLC.
\end{abstract}

Keywords: HMI, CX-Designer, PLC

\section{Pendahuluan}

Pendidikan merupakan suatu usaha yang dilakukan secara sistematis sesuai dengan tanggung jawab yang diberikan, hal ini menjadikan peserta didik (mahasiswa) terpengaruhi serta memiliki sifat yang diharapkan oleh suatu pendidikan (Munib, 2004). Harapan tersebut mengarah pada proses pendewasaan diri sehingga menjadikan peserta didik lebih mandiri nantinya. Salah satu dalam mencapai hal tersebut yaitu dengan meningkatkan efesiensi dan efektifitas dalam proses belajar mengajar yang dikembangkan dalam bentuk proses inovasi terhadap model pembelajaran.

Berdasarkan hasil pengamatan terhadap pembelajaran Programmable Logic Controller yang selanjutnya disingkat PLC, ditemukan fakta bahwa interaksi dalam proses belajar mengajar terkesan pasif, mahasiswa hanya sebagai pendengar yang mengakibatkan proses pembelajaran menjadi terhambat. Terdapat beberapa faktor yang menghambat pembelajaran tersebut seperti kurangnya media pembelajaran praktikum PLC, bervariasinya trainer PLC sehingga setiap mahasiswa harus mempelajari trainer sebelum digunakan, terbatasnya alat praktikum seperti kabel jumper, sakelar, dan lampu indikator dikarenakan sebagian besar mengalami kerusakan. Faktor-faktor tersebut menyebabkan mahasiswa kurang memahami materi pembelajaran.
Dibutuhkannya suatu media pembelajaran yang mumpuni bagi setiap mahasiswa dalam praktikum agar kompetensi yang dibutuhkan tercapai dengan baik. Media pembelajaran dalam mata kuliah ini menjadi sangat penting agar ketika mahasiswa dalam melakukan suatu praktikum tidak terjadi kebingungan serta turunnya minat dan motivasi dalam belajar. Media pembelajaran merupakan salah satu pokok dalam mencapai tujuan pembelajaran, penyaluran bahan ajar dalam bentuk media yang interaktif dapat menimbulkan rangsangan terhadap minat, perasaan, perhatian dan pikiran (Daryanto, 2013). Salah satu media yang dapat menyelesaikan masalah tersebut adalah rancang bangun simulasi trainer HMI berbasis CXDesigner yang dapat digunakan setiap mahasiswa dalam pembelajaran PLC.

Human Machine Interface (HMI) merupakan suatu software yang berguna dalam mengontrol serta memonitoring suatu proses di industri, dengan tujuan meningkatkan efektifitas, efesiensi dan kepuasan dalam penggunaannya (Fiset, 2009). Trainer HMI merupakan media pembelajaran bersifat simulasi, model simulasi tersebut bertujuan untuk memberikan suatu pengalaman yang lebih nyata melalui pembuatan contoh-contoh serta bentuk pengalaman yang menyerupai lingkungan yang sebenarnya tanpa risiko yang berbahaya (Rusman, 2012). 


\section{Metode Penelitian}

Metode penelitian yang digunakan adalah rancang bangun. Rancang merupakan suatu proses tahapan kegiatan untuk mengartikan atu menterjemahkan hasil analisis dari sebuah sistem ke bahasa pemrograman untuk menggambarkan secara jelas dan terperinci suatu komponen sistem yang diterapkan (Pressman, 2010). Bangun/ pembangunan sistem adalah usaha dalam membuat atau mengadakan suatu sistem yang baru atau menggantikan serta memperbaiki sistem yang telah ada secara menyeluruh atau sebagian.

Dapat disimpulkan bahwa rancang bangun merupakan suatu aktivitas pekerjaan yang menerjemahkan perolehan analisis ke dalam wujud software yang selanjutnya dikembangkan pada sistem yang sudah ada. Dalam penelitian ini, rancang bangun yang dilakukan dengan cara eksperimen, yaitu menghasilkan produk berupa modul latihan otomasi HMI berbasis CX-Designer yang terintegrasi dengan PLC Omron.

\section{Hasil dan Pembahasan}

PLC yang digunakan dalam penelitian ini yaitu Model PLC Omron Sysmac CP1L yang memiliki 40 buah Input/Output (I/O). Berikut contoh nama-nama komponen dari PLC CPIL (OMRON, 2009), di antaranya (1) Memory cassete slot; (2) Perpheral USB port; (3) Analog adjuster; (4) External analog settings input connector; (5) DIP switches; (6) Battery; (7) Operation indicator; (8) Power supply, ground, and input terminal block; (9) Input indicators; (10) Option board slot; (11) Expansion I/O unit connector; (12) Output indicators; (13) External power supply and output terminal block; dan (14) DIN track mounting pin.

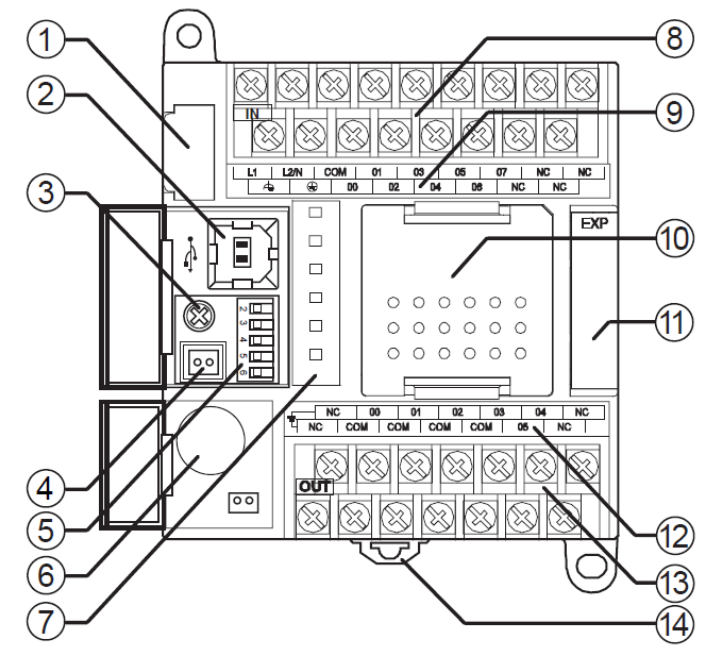

Gambar 1. PLC CP1L dengan 40 I/O (OMRON, 2009)
Software yang digunakan untuk menjalankan PLC ini yaitu CX-Programmer dengan penulisan program menggunakan metode pemrograman tangga (ladder programming). Selain fungsi pemrograman, software ini juga dapat berfungsi sebagai pengaturan dan pengoperasian PLC, seperti program debugging, menampilkan alamat dan nilai, pengaturan dan pemantauan, dan pemrograman jarak jauh melalui jaringan.

Metode pemrograman tangga ini menyajika suatu cara dalam penulisan kode program yang selanjunya akan diubah menjadi kode mesin sehingga kode tersebut dapat diterjemahkan oleh mikroprosesor di PLC. Penulisan suatu kode program ini serupa dengan menuliskan sebuah rangkaian pensakelaran di rangkaian listrik atau instalasi listrik. Diagram tangga pada PLC terdiri dari dua garis horizontal yang berguna untuk pengisian komponen-komponen $\mathrm{I} / \mathrm{O}$ dan fungsi dalam bentuk rangkaian anak tangga di antara dua garis vertikal yang menggambarkan garis daya suatu listrik.

Pemrograman tangga dalam penelitian ini menggunakan software CX-Programmer yang terintegrasi secara penuh ke semua tipe PLC Omron. Berikut adalah langkah-langkah dalam membuat program tangga menggunakan $\mathrm{CX}$ Programmer untuk PLC CP1L:

\section{a. Membuat Proyek Baru}

Saat menggunakan CX-Programmer pertama kali yang harus dilakukan adalah membuat proyek baru. Caranya dengan memilih [file] - [New] atau menekan "Ctrl $+\mathrm{N}$ " atau dengan mengklik tombol "New" pada [File Toolbar].

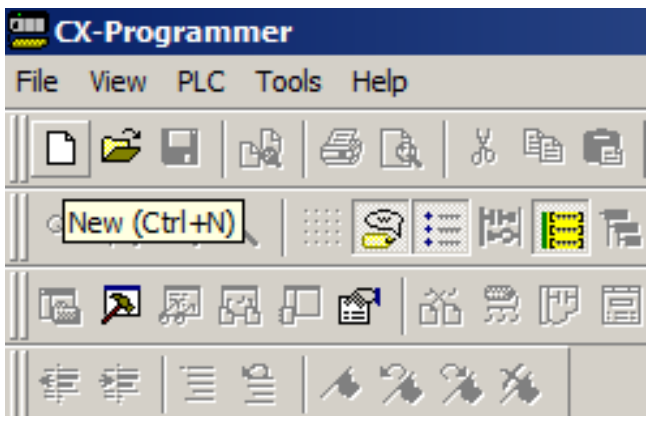

Gambar 2. Membuat Proyek Baru

\section{b. Menetapkan Tipe Perangkat PLC}

Penetapan tipe perangkat PLC ini dilakukan agar pemograman tangga dan alamat yang dibuat sesuai dengan PLC yang digunakan, jika hal ini tidak dilakukan maka program yang sudah dirancang akan 
menampilkan tabel error atau tidak bisa terbaca atau tidak berjalan sesuai dengan yang diinginkan. Menetapkan "Device Type" dengan memilih [CP1L]. Memilih "CPU Type" dengan mengklik [Settings] - [L]. Mengkonfirmasi [USB] sebagai "Network Type".

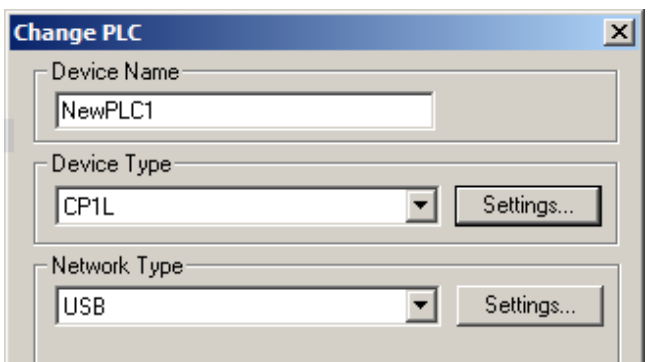

Gambar 3. Penetapan Tipe Perangkat PLC

\section{c. Lembaran Kerja di CX-Programmer}

Setelah pengaturan tipe PLC pada dialog box diselesai, maka akan muncul tampilan utama untuk new project. Pada lembaran kerja inilah pemrograman tangga dapat ditulis, diedit, serta disimulasikan. Banyaknya kolom pada lembaran kerja dapat diatur jumlahnya, hal ini bertujuan untuk menyesuaikan seberapa banyak I/O yang digunakan. Pada penelitian ini jumlah kolom pada lembaran kerja dibatasi sebanyak empat buah. Tampilan lembaran kerja di CXProgrammer ditunjukkan pada Gambar 4.

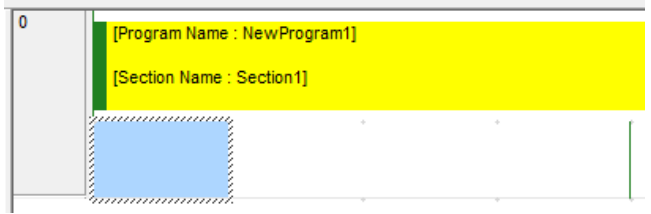

Gambar 4. Lembaran Kerja di CX-Programmer

\section{d. Memasukkan Kode Pemrograman Tangga}

Sebelum memasukkan kode program, operator harus menentukan terlebih dahulu jumlah I/O yang digunakan. Pada pengetesan simulasi trainer PLC CP1L, peneliti membatasi jumlah input sebanyak dua buah yaitu satu kontak push button dengan tipe momentary untuk menghidupkan lampu indikator (PB ON) dengan alamat 0.00 , dan satu kontak push button dengan tipe momentary untuk mematikan lampu indikator (PB OFF) dengan alamat 0.01. Bagian output sebanyak satu buah yang berupa lampu indikator dengan alamat 100.00 yang akan menerima sinyal dari alamat 0.00 dan 0.01. Berikut langkah-langkah memasukkan program tangga ke dalam lembar kerja dan tampilan kode program ditunjukkan pada Gambar 5.

1) Memasukkan kontak NO/Normally Open (Load Bit/LD) dengan mengetik huruf "C" pada kolom dan baris pertama.

"I: 0.00" bermakna "I" Input dengan Bit 0.00 dan komentar I/O "PB ON" (Sakelar Push Button ON);

2) Memasukkan kontak NC/Normally Closed (Load Bit Not/LDNOT) dengan mengetik karakter "/" pada baris pertama dan kolom ke dua.

"I: 0.01" bermakna "I" Input dengan Bit "0.01" dan komentar I/O "PB OFF" (Sakelar Push Button OFF);

3) Memasukkan Output Coil (Out) dengan mengetik "O" pada baris pertama dan kolom terakhir/kolom ke empat.

"Q: 100.00" bermakan "Q" Output dengan Bit "100.00" dan komentar I/O "LAMPU" (Indikator Output).

4) Memasukkan rangkaian OR (OR Bit) dengan mengetik "C" pada baris ke dua (pada baris tangga pertama) dan kolom pertama

"Q: 100.00" bermakan "Q" Output dengan Bit "100.00" dan komentar I/O "LAMPU" (Indikator Output);

Q: 100.00

Gambar 5. Kode Pemrograman Tangga

e. Operasional/Instruksi Program

Instruksi suatu program dibutuhkan agar operator dapat mengerti dalam menjalankan setiap fungsi $\mathrm{I} / \mathrm{O}$. Secara lengkap instruksi yang dirancang pada pengetesan ini adalah sebagai berikut:

1) Jika tombol "PB ON (I: 0.00)" ditekan maka "LAMPU (Q: 100.00)" akan hidup $(\mathrm{ON})$

2) Jika tombol "PB ON (I: 0.00)" dilepas maka "LAMPU (Q: 100.00)" tetap hidup $(\mathrm{ON})$;

3) Jika tombol "PB OFF (I: 0.01)" ditekan maka "LAMPU (Q: 100.00)" akan mati (OFF);

4) Jika tombol "PB OFF (I: 0.01)" dilepas maka "LAMPU (Q: 100.00)" tetap mati (OFF). 
Pembuatan HMI dalam penelitian ini menggunakan software CX-Designer buatan Omron yang berfungsi untuk memvisualisasikan kerjaan, peristiwa, ataupun proses yang sedang terjadi secara nyata dengan membuat simulasinya terlebih dahulu. HMI juga berguna bagi operator dalam mendeteksi error dalam program sebelum program tersebut dijalankan ke sistem sebenarnya dalam sebuah industri. Berikut diagram garis besar alur pengerjaan di CX-Designer pada Gambar 6.

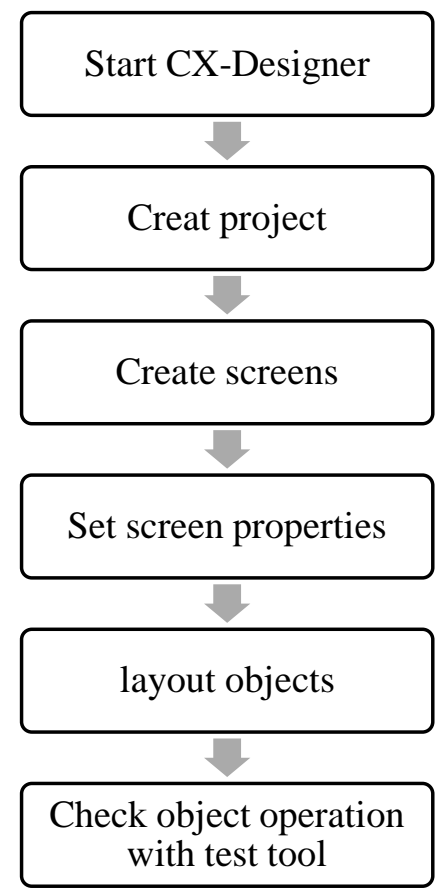

Gambar 6. Diagram Garis Besar Alur Operasi pada CX-Designer

a. Pembuatan Awal Proyek

Awal pembuatan simulasi trainer PLC di

CX-Designer hampir sama dengan awal pembuatan pemrograman tangga di software CX-Programmer. Langkah-lankah yang harus dilakukan adalah dengan memilih [File] - [New Project] atau dengan mengklik tombol "New Project" pada [File Toolbar].

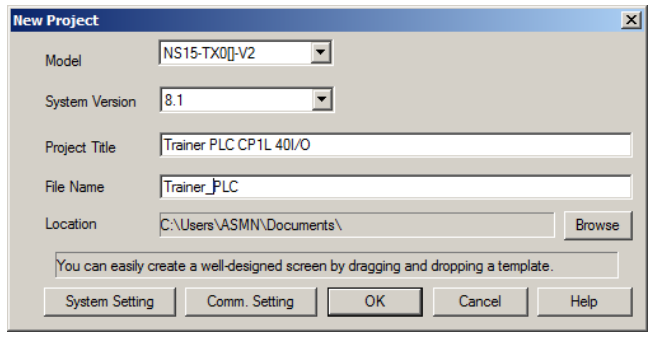

Gambar 7. Pembuatan Awal Proyek di CXDesigner

\section{b. Membuat Layar Baru/New Screen}

Pembuatan layar pada CX-Designer bertujuan untuk menentukan jumlah layar yang akan digunakan dalam simulasi. Dalam pembuatan simulasi trainer PLC ini peneliti menggunakan tiga layar yang terdiri dari layar pertama untuk tampilan awal trainer, layar kedua untuk operasi I/O dalam bentuk penggunaan sakelar toggle, dan layar ketiga untuk operasi I/O dalam bentuk penggunaan sakelar push button tipe momentary.

Pembuatan layar baru dapat dilakukan dengan dua cara, yaitu ketika di awal pembuatan dengan memilih langsung menu [File] - [New Screen] atau ketika sudah berjalan dengan memilih di [Project Workspace] [Screen/Sheet] - [New Screen]. Tampilan pembuatan layar baru ditunjukkan pada Gambar 8.

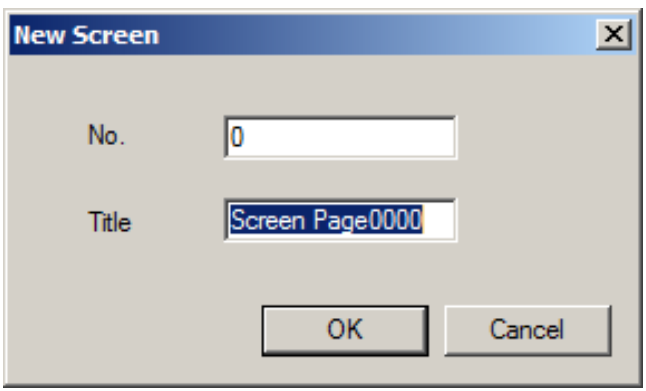

Gambar 8. Pembuatan Layar Baru di CXDesigner

\section{c. Pengaturan Properti Layar}

Pengaturan ini berfungsi untuk pembuatan judul dari setiap layar, mengatur jenis layar editing dan ukuran layar, serta menetapkan latar belakang layar dan pengaturan kompresi file data yang digunakan.

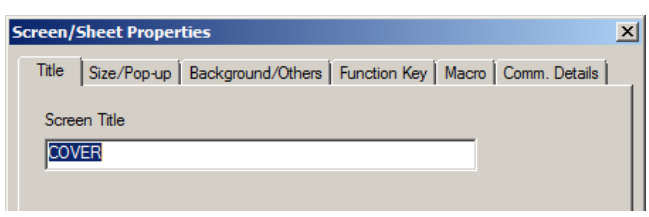

Gambar 9. Properti Layar di CX-Designer

\section{d. Layar Objek Pertama}

Tampilan pertama ketika simulasi dijalankan adalah layar depan yang memperlihatkan judul trainer PLC disertai gambar PLC tipe CP1L dengan 40 I/O. Bagian bawah layar pertama ini berisi pilihan sakelar dalam pengoperasian PLC, yaitu pilihan input sakelar toggle dan pilihan input sakelar push 
button dengan tipe momentary. Tampilan objek pertama ditunjukkan pada Gambar 10.

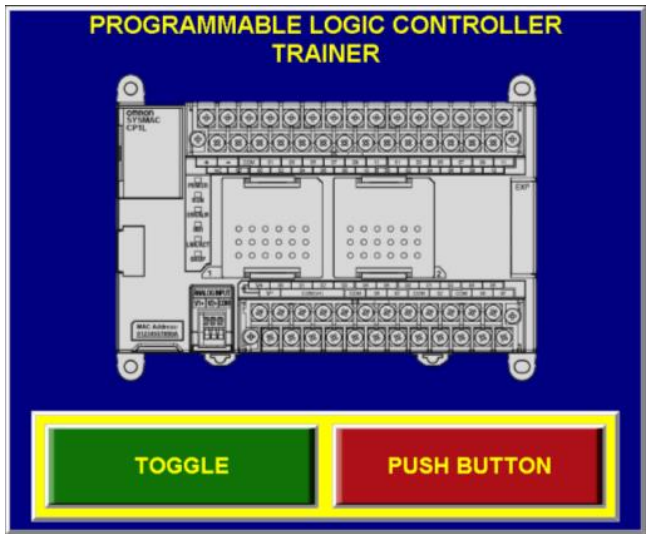

Gambar 10. Tampilan Layar Objek Pertama

\section{e. Layar Objek Kedua}

Tampilan objek pada layar kedua memperlihatkan suatu input berupa sakelar toggle tipe momenary sebanyak 24 buah (kolom atas) dengan dua alamat. Alamat $0 \mathrm{CH}$ sebanyak 12 buah, yaitu bit 00 sampai dengan bit 11, dan alamat $1 \mathrm{CH}$ sebanyak 12 buah, yaitu bit 00 sampai dengan bit 11.

Bagian output berupa lampu indikator sebanyak 16 buah (kolom bawah) dengn dua alamat. Alamat $100 \mathrm{CH}$ sebanyak 8 buah, yaitu bit 00 sampai dengan bit 07 , dan alamat $101 \mathrm{CH}$ sebanyak 8 buah, yaitu bit 00 sampai dengan bit 07.

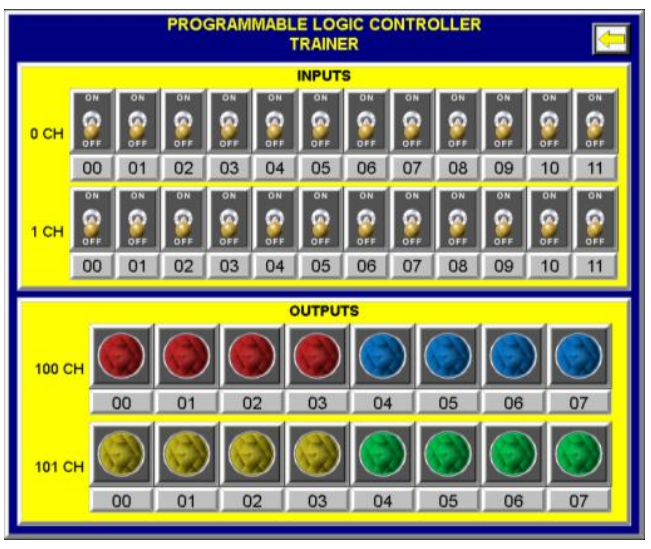

Gambar 11. Tampilan Layar Objek Kedua

\section{f. Layar Objek Ketiga}

Tampilan pada layar ketiga memperlihatkan suatu input berupa sakelar push button tipe momentary sebanyak 24 buah (kolom atas) dengan dua alamat. Alamat $0 \mathrm{CH}$ sebanyak 12 buah, yaitu bit 00 sampai dengan bit 11 , dan alamat $1 \mathrm{CH}$ sebanyak 12 buah, yaitu bit 00 sampai dengan bit 11 .
Bagian output berupa lampu indikator sebanyak 16 buah (kolom bawah) dengn dua alamat. Alamat $100 \mathrm{CH}$ sebanyak 8 buah, yaitu bit 00 sampai dengan bit 07 , dan alamat $101 \mathrm{CH}$ sebanyak 8 buah, yaitu bit 00 sampai dengan bit 07.

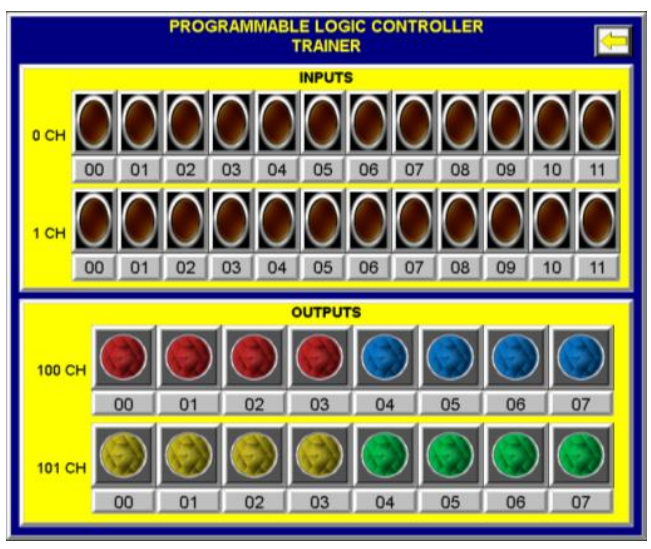

Gambar 12. Tampilan Layar Objek Ketiga

\section{g. Eksekusi dan Pengetesan Program}

Tombol perintah eksekusi pengujian kode program dapat dilakukan di CX-Designer dan CX-Programmer. Pada pengetesan kode program ini peneliti melakukan eksekusi atau pengetesan melalui CX-Programmer. Berikut adalah proses tahapan dalam melaksanakan pengetesan dengan menekan tombol "PLC-PT Integrated Simulation" dan "Start". Setelah dilakukan tahapan tersebut maka proses pemindahan data untuk simulasi dimulai.

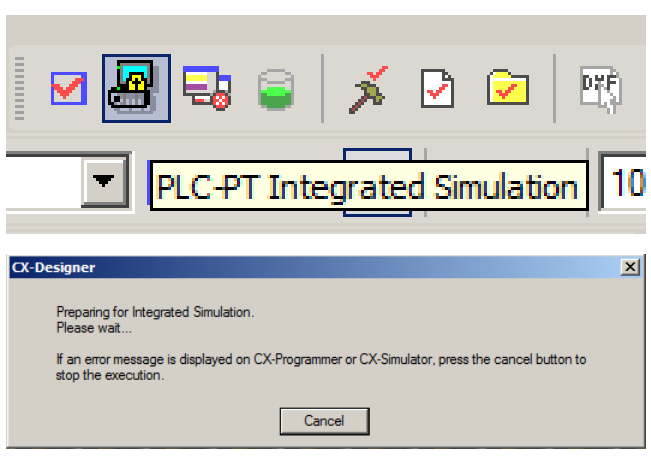

Gambar 13. Tombol Eksekusi Pengetesan Program

h. Pengujian Simulasi Trainer PLC CP1L

Setelah proses sinkronisasi selesai maka akan muncul tampilan menu "Test Mode" seperti Gambar 14. Tampilan awal simulasi trainer PLC akan menampilkan pilihan sakelar yang dapat digunakan dengan cara ditekan. Tampilan pemrograman tangga pada CXProgrammer juga akan terintegrasi dengan 
simulasi, artinya apa yang terjadi di "Test Mode" akan terlihat juga pada rangkaian pemrograman tangga. Berikut tampilan simulasi trainer di "Test Mode" dan pemrograman tangga di software CX-Programmer yang ditunjukkan pada Gambar 14.
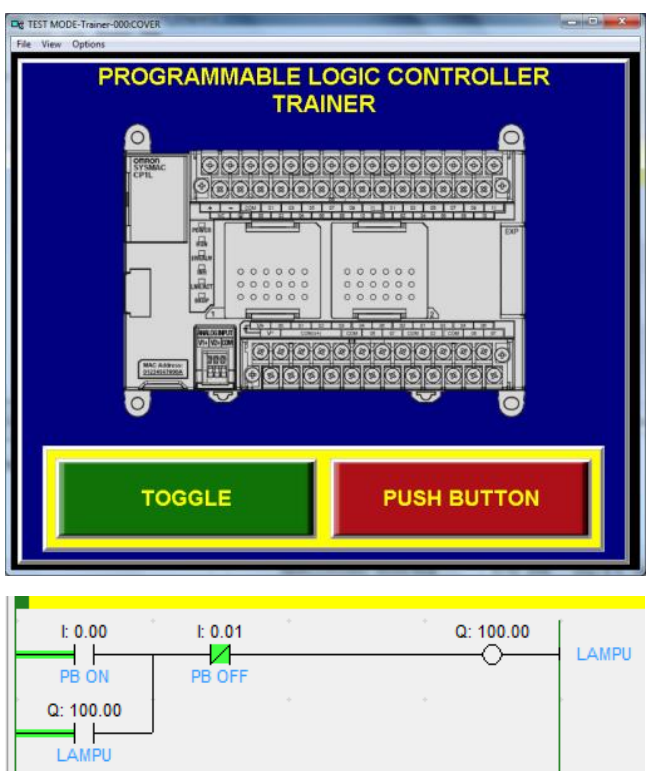

Gambar 14. Kondisi Awal Simulasi

Pengetesan dalam simulasi trainer ini adalah contoh dari prinsip kerja rangkaian pengunci. Rangkaian pengunci merupakan suatu rangkaian yang dapat mempertahankan kondisi keluaran ketika kondisi masukan berubah. Jenis rangkaian ini sering digunakan dalam aplikasi sakelar pada PLC karena memiliki mekanisme yang mudah dan sederhana dalam pengoperasiannya. Berikut dilakukan sebuah pengetesan dengan menggunakan layar ketiga trainer dengan cara menekan tombol merah bertulisan "PUSH BUTTON" pada layar pertama simulasi trainer yang ditunjukkan di Gambar 14. Setelah tampilan ketiga muncul lakukan pengetesan sesuai langkah-langkah berikut:

\section{1) Pengetesan Pertama}

Jika tombol "PB ON (I: 0.00)"

ditekan maka "LAMPU (Q: 100.00)" akan hidup (ON). Tombol "PB ON" dengan alamat " 0.00 " pada kotak "INPUT" menyala berwarna kuning ketika ditekan. Pada kotak "OUTPUT" lampu indikator dengan alamat 100.00 berwarna merah menyala. Pada tampilan di CX-Programmer akan terlihat garis berwarna hijau dari input menuju ke output dengan kondisi terhubung.

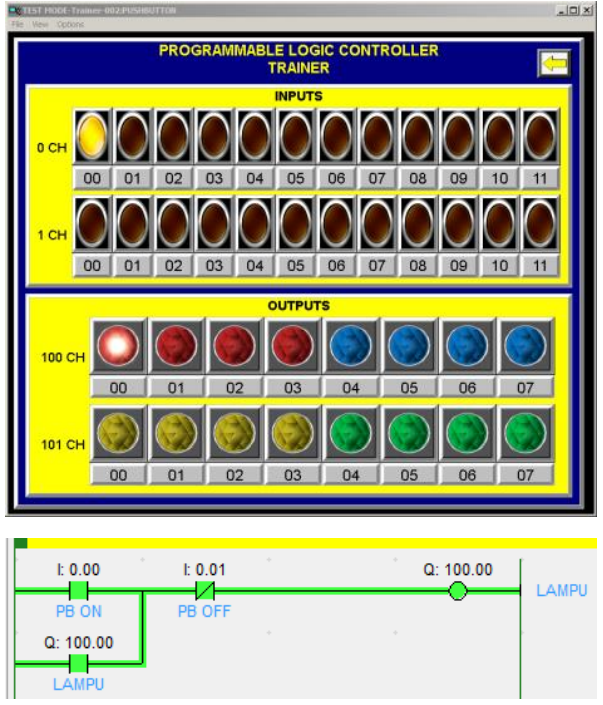

Gambar 15. Operasi Ketika Tombol "PB ON" Ditekan

\section{2) Pengetesan Kedua}

Jika tombol "PB ON (I: 0.00)" dilepas maka "LAMPU (Q: 100.00)" tetap hidup $(\mathrm{ON})$. Tombol "PB ON" dengan alamat "0.00" pada kotak "INPUT" tidak menyala ketika dilepas. Pada kotak "OUTPUT" lampu indikator dengan alamat 100.00 berwarna merah teta menyala. Pada tampilan di CX-Programmer akan terlihat garis berwarna hijau dari input menuju ke output tertap terhubung.

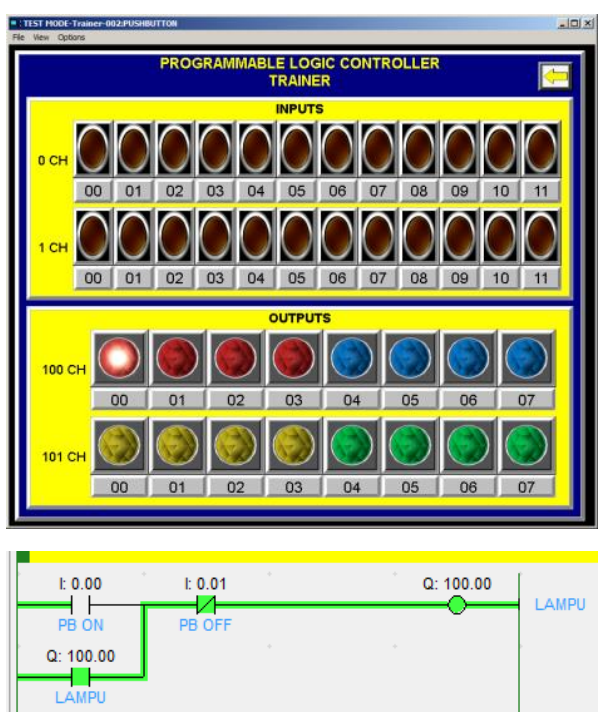

Gambar 16. Operasi Ketika Tombol "PB ON" Dilepas

3) Pengetesan Ketiga

Jika tombol "PB OFF (I: 0.01)" ditekan maka "LAMPU (Q: 100.00)" akan mati (OFF). Tombol "PB OFF" dengan 
alamat "0.01" pada kotak "INPUT" menyala berwarna kuning ketika ditekan. Pada kotak "OUTPUT" lampu indikator dengan alamat 100.00 berwarna merah tidak menyala. Pada tampilan di CX-Programmer akan terlihat garis berwarna hijau dari input menuju ke output terputus.

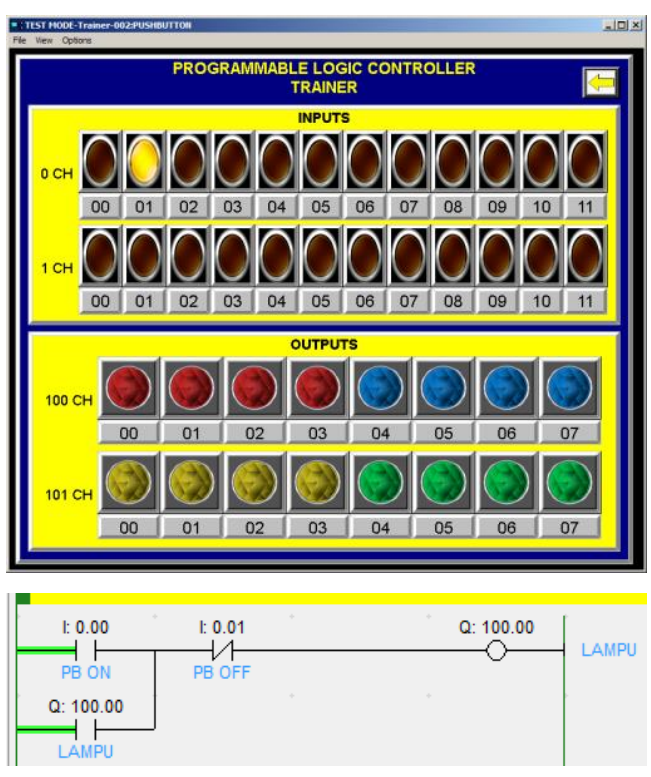

Gambar 17. Operasi Ketika Tombol "PB OFF" Ditekan

\section{4) Pengetesan Keempat}

Jika tombol "PB OFF (I: 0.01)" dilepas maka "LAMPU (Q: 100.00)" tetap mati (OFF). Tombol "PB OFF" dengan alamat "0.01" pada kotak "INPUT" tidak menyala berwarna kuning ketika dilepas. Pada kotak "OUTPUT" lampu indikator dengan alamat 100.00 berwarna merah tidak menyala. Pada tampilan di CX-Programmer akan terlihat garis berwarna hijau dari input menuju ke output terputus.

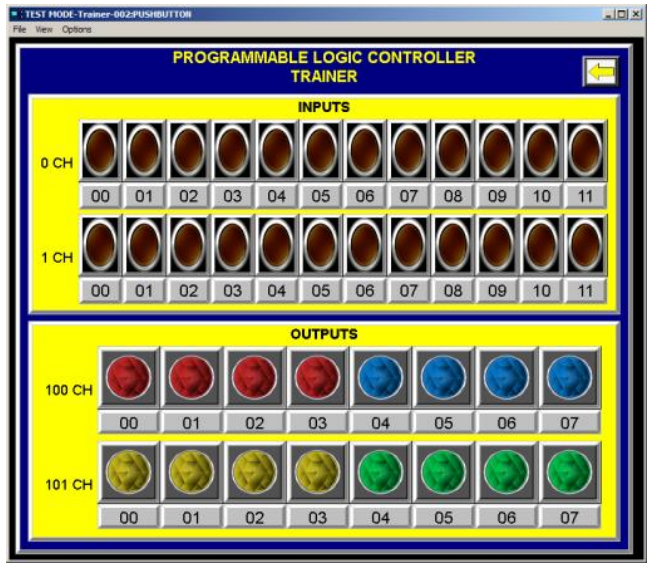

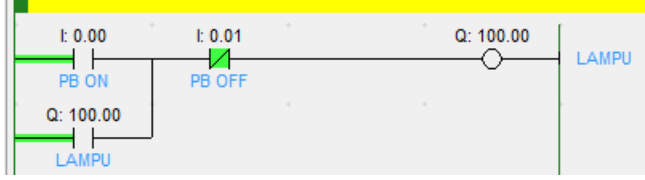

Gambar 18. Operasi Ketika Tombol "PB OFF" Dilepas

\section{Kesimpulan}

Berdasarkan penelitian yang telah dilakukan dapat disimpulkan bahwa rancang bangun suatu alat simulasi trainer PLC dapat berjalan dengan baik dan benar. Pemilihan sakelar yang dapat dipilih sebelum operasi dijalankan memberikan suatu kemudahan dalam praktikumnya tanpa harus mengganti komponen terlebih dahulu yang dapat membuang waktu dalam pengerjaannya. Banyaknya I/O dalam simulasi trainer memberikan suatu jalan untuk dapat diaplikasikan ke suatu sistem pengontrolan yang lebih besar. Dengan kemudahan dan fleksibilitas ini seorang operator dalam memelajari PLC akan memiliki motivasi dan minat serta terlatih untuk menyelesaikan masalah dibidang sistem kontrol di PLC, hal ini terjadi dikarenakan seorang operator memperoleh visual yang jelas dan lagngsung mengenai sistem yang dirancangnya.

\section{Daftar Pustaka}

Daryanto. (2013). Media Pembelajaran. Yogyakarta: Gava Media

Fiset, J. Y. (2009). Human-Machine Interface Design for Process Control Applications. USA: ISAInstrumentation, System, and Automation Society.

Munib, A. (2004). Pengantar Ilmu Pendidikan. Semarang: UPT MKK UNNES.

OMRON. (2009). SYSMAC CPIL/CPIE CPU Unit : Introduction Manual. Tokyo, JAPAN: OMRON Corporation.

Pressman, R. (2010). Software Engineering : a practitioner's approach. New York: McGrawHill.

Rusman. (2012). Belajar dan Pembelajaran Berbasis Komputer. Bandung: Alfabeta. 